\title{
A Group Visit Initiative Improves Advance Care Planning Documentation among Older Adults in Primary Care
}

\author{
Hillary D. Lum, MD, PhD, Rebecca L. Sudore, MD, Daniel D. Matlock, MD, MPH, \\ Elizabeth Juarez-Colunga, PhD, Jacqueline Jones, PhD, RN, Molly Nowels, MA, \\ Robert S. Schwartz, MD, Jean S. Kutner, MD, MSPH, and Cari R. Levy, MD, PhD
}

Introduction: Group visits for advance care planning (ACP) may help patients document preferences for decision makers and future care. We assessed the impact of a primary care-based ACP group visit (ACPGV) intervention on older adults' ACP documentation and why patients participated.

Methods: Older adults (>65 years) in primary care participated in a 2-session ACP-GV intervention that promotes group dynamics, peer-based learning, and goal setting. Charts were reviewed at baseline, 3 months, and 12 months for documentation of decision makers and ACP forms. We described patients' reasons for participating through analysis of transcripts.

Results: 118 patients (mean age 76 years; 62\% female and $82 \%$ white) participated in 16 ACP-GV cohorts. From baseline to 3 -month follow-up, documentation of decision maker preferences increased from $39 \%$ to $81 \%$, and was $89 \%$ at 12 -month follow-up. Patients with completed ACP forms increased from $20 \%$ to $57 \%$ at 3 months, and was $67 \%$ at 12 months. Reasons for participating included recognizing the importance of ACP, curiosity, participation recommended by primary care provider, desire to talk with family/friends, and desire to complete advance directives.

Conclusions: This ACP-GV intervention increased ACP documentation among patients with diverse reasons for participating. This is a patient-centered approach to ACP in primary care. (J Am Board Fam Med 2017;30:480-490.)

Keywords: Advance Care Planning, Advance Directives, Decision Making, Documentation, Palliative Care, Patient Appointments, Primary Health Care

To provide high-quality care, primary care settings need innovative clinical interventions to engage patients in advance care planning (ACP). ${ }^{1}$ In recent

\footnotetext{
This article was externally peer reviewed.

Submitted 8 February 2017; revised 8 February 2017; accepted 13 February 2017.

From the Divisions of Geriatric Medicine (HDL, DDM, RSS) and General Internal Medicine (JSK), Department of Medicine, University of Colorado School of Medicine, Anschutz Medical Campus, Aurora; the Veterans Affairs Eastern Colorado Geriatric Research, Education and Clinical Center, Denver (HDL, DDM, RSS); the Division of Geriatrics, Department of Medicine, University of California, San Francisco (RLS); the San Francisco VA Medical Center, San Francisco (RLS); the Adult and Child Center for Health Outcomes Research and Delivery Science, University of Colorado, Anschutz Medical Campus, Aurora (DDM, EJC); the Colorado School of Public Health, Anschutz Medical Campus, Aurora (EJC, $\mathrm{MN})$; the University of Colorado College of Nursing, Anschutz Medical Campus, Aurora (JJ); and the Denver-Seattle Center on Innovation for Veteran-Centered and Value-Driven Care, Denver VA Medical Center, Denver, CO (CRL).
}

surveys of US adults aged $\geq 65$ years, $67 \%$ reported having a written plan naming a surrogate decision maker, 55\% reported having a written plan describ- 
ing treatment they want near the end of life, but only $27 \%$ reported discussing end-of-life care with a physician. ${ }^{2,3}$ Furthermore, within these surveys, it is unknown whether respondents' ACP preferences or discussions were documented in medical records. ACP conversations are associated with improved outcomes including satisfaction, quality of life, and receipt of medical care aligned with patient wishes. ${ }^{4-7}$ However, patients and clinicians face barriers to implementing these conversations into routine primary care. ${ }^{8-12}$ Barriers for physicians include lack of time and training; barriers for older adults include lack of understanding and wanting to include loved ones who are unavailable or uninterested. ${ }^{3,13}$ ACP interventions, such as patient decision aids (eg, websites, videos, card games) ${ }^{14-16}$ and care models (eg, trained facilitators), ${ }^{17}$ have been tested, ${ }^{18}$ but the use of these strategies in routine medical care remains limited. ${ }^{19,20}$

Group visits may be an effective primary care initiative both to engage patients in ACP discussions and to expand health care providers' capacity to facilitate education, counseling, and documentation. Group visits are a format for health care delivery that brings groups of patients together for medical care, education, and patient engagement. ${ }^{21,22}$ They demonstrate improved disease management among patients with diabetes, hypertension, or multiple chronic conditions and have been integrated into several ambulatory settings. ${ }^{23-25}$ Key strengths of group visits include high-quality education and supportive discussions, patient and provider satisfaction, and improved patient self-efficacy. ${ }^{26-28}$ Although ACP counseling has traditionally occurred in 1-on-1 patient-provider interactions, support from peers in the group visit setting creates a group dynamic that may promote patient engagement in ACP by improving knowledge, supporting values-based discussions, and promoting decision making about future medical care. In the United States and Canada, support for group visits in primary care is increasing ${ }^{29,30}$ and may represent a practical opportunity to implement ACP discussions.

We developed an innovative ACP group visit intervention. ${ }^{31}$ One goal of the intervention is to improve ACP documentation for older adults in

Corresponding author: Hillary D. Lum, MD, PhD, 12631 E. 17th Ave, Campus Mail Stop B179, Aurora, CO 80045 (E-mail: hillary.lum@ucdenver.edu). primary care settings. We previously reported that older adults who participated in the intervention were willing to share personal values and challenges related to ACP, initiated discussions about a range of relevant topics, and reported a higher rate of engaging in detailed conversations about ACP. ${ }^{31}$

This study focuses on whether participation in an ACP group visit intervention for older adults increases documentation filed within the health care system of either surrogate decision maker(s) or goals for medical care in an ACP document compared with before the intervention. To enhance understanding of feasibility, acceptability, and reproducibility, we also sought to describe reasons why patients chose to participate in this innovative ACP group visit intervention.

\section{Methods \\ Context}

The ACP group visit intervention was conducted as a clinical demonstration project in 3 primary care clinics at University of Colorado Hospital, Aurora (UCHA), using a pre-/post-intervention evaluation design. This health care system has group visits for patients with diabetes, interest in weight loss, or nonepileptic seizures, though none of these group visits address ACP. The ACP group visit intervention was integrated into the existing workflows of each primary care clinic between November 2013 and June $2015 .^{32}$ The project was developed with input from clinical leadership, staff, and patient stakeholders and was approved by the Colorado Multiple Institutional Review Board as a quality improvement initiative. This report follows the Standards for Quality Improvement Reporting Excellence 2.0 guidelines. ${ }^{33}$ All patients signed a clinical consent form acknowledging voluntary participation, including audio-recording of group visits.

\section{Intervention}

The ACP group visit structure with a description of the facilitators' guide and implementation strategy has been published. ${ }^{31}$ Briefly, the intervention schedules up to 10 patients (age $\geq 65$ years) to participate in 2 group visits, each 2 hours long, 1 month apart, facilitated by a physician and social worker pair who used a facilitators' guide to conduct a semistructured group interaction. Both facilitators had some preliminary experience facilitating group visits for older adults and iteratively 
refined the facilitators' guide based on intervention session debriefings. The intervention combines principles from existing group visit models, ${ }^{23}$ collaborative learning theory, ${ }^{34}$ and ACP behavior change models. ${ }^{8,9}$ Collaborative learning theory emphasizes that (1) learning is a social experience, (2) learners have diverse experiences and learning styles, and (3) learning includes individual experiences alongside factual knowledge (ie, medical expertise). The first session focused on sharing personal stories related to ACP experiences, consideration of personal values, and the role of surrogate decision makers. The second session focused on identifying and communicating personalized steps related to ACP (eg, talking with a trusted person, choosing surrogate decision makers, and documenting preferences in advance directives). Multiple teaching methods and ACP resources, such as the Conversation Starter $\mathrm{Kit}^{35}$ and PREPARE, ${ }^{14}$ an evidenced-based patient resource available online, were used to meet patients' diverse learning styles. Medical assistants and schedulers were present to provide support, consistent with group visit models. ${ }^{32}$

Because ACP is a process that includes choosing surrogate decision makers and documenting preferences in advance directives, the ACP group visit intervention provided specific support for these activities. Patients were encouraged to bring copies of preexisting or new advance directive documents or out-of-hospital orders to be scanned into the electronic medical record (EMR), because having documents available within the health care system is increasingly recognized as an important part of ACP. ${ }^{18}$ Patients could verbally choose a medical proxy decision maker if they were not yet ready to complete a written medical durable power of attorney (MDPOA) form. Individuals who verbally selected a medical proxy decision maker were encouraged to complete a legal MDPOA form, which was available during the sessions. Details on clinical documentation and billing for the ACP group visit intervention have been published. ${ }^{31}$

\section{Patients and Recruitment}

Patients could participate if they were aged $\geq 65$ years and received primary care at 1 of 3 primary care clinics at the UCHA. Patients were recruited to participate in the intervention using multiple methods as part of clinical care. Referral sources included primary care clinicians, invitation letters sent to patients with the permission of the patient's primary care provider, self-referral via clinic-based flyers, or referral by family or a friend. We encouraged clinicians to refer patients they felt would benefit from and be able to participate in a group setting, that is, patients who did not have significant cognitive, hearing, or mental health impairments. We did not screen for nor exclude patients based on any of these potential impairments. ACP is a process with multiple steps. Because changes in health status or preferences can prompt updates or revisions to documents, patients who had previously engaged in ACP were not excluded. Clinicians were not asked to prioritize patients with poor health status, difficulty with ACP, or known endof-life needs. Interested patients received a letter on behalf of their primary care clinician that briefly described the intervention as well as a follow-up telephone call from the program coordinator to describe the program and schedule the 2 sessions. If the patient's medical record listed a spouse or partner, we asked the patient whether the spouse or partner also received primary care from any UCHA primary care clinic, which enabled communication with their primary care clinician via the EMR. If both were patients at UCHA, they were invited to participate together in the ACP group visit intervention. For patients who declined to be scheduled after the telephone outreach call, they were asked to provide a reason for declining. Reasons were coded as "not interested," "moving out of area," "illness/not feeling well," "transportation issue," "already completed advance directive," "already had a conversation," "other," and no reason given.

\section{Evaluation Measures}

Patient age, sex, and insurance type were abstracted from the EMR at the time of referral. Patients provided demographic characteristics, stated whether they had been a caregiver in the past 12 months, and responded to the PROMIS global health self-reported item: "In general, would you say your health is: excellent, very good, good, fair, poor." ${ }^{36,37}$ Referral source was recorded during the scheduling process.

\section{ACP Documentation}

To assess the impact of this clinical demonstration project, we conducted before-and-after assessments of the ACP group visit intervention. Charts were 
reviewed for documentation of surrogate decision makers or ACP documents at baseline and 3 and 12 months. EMR documentation of decision makers included (1) written selection of a MDPOA in a legal document or 2) verbal selection of a medical proxy decision maker, which is documented in a specific ACP section of the EMR. For inclusion in the results as having ACP forms, the patients had to have at least 1 document present in the EMR. These documents could include MDPOA forms, living wills, Colorado Medical Orders for Scope of Treatment forms, or cardiopulmonary resuscitation directives.

\section{Analysis}

We conducted a mixed-methods analysis. First, descriptive statistics were collected to describe patient characteristics. The Student $t$ test was used to compare age, sex, and insurance type for participants and nonparticipants. The McNemar test was used for before-and-after intervention comparisons of surrogate decision maker documentation or ACP documents between baseline and the 3-month follow-up and between baseline and the 12-month follow-up.

Based on emerging patterns from the ACP documentation analysis and our observations that diverse patients seemed to be participating, we used applied qualitative content analysis to identify unique categories for participants' reasons for participating. ${ }^{38}$ All group visit sessions were audiorecorded and transcribed. Patient identifiers were redacted from transcripts. Discrete data were extracted from each group session at the level of the individual. Specifically, we identified participants' statements at the beginning of the first group session, when each person introduced themselves to the group and answered the question, "Why did you think coming to this group was a good use of your time today?" The descriptive analysis involved systematic organization of the data, open coding of reasons for participating, and repeated, constant comparison across coded data to identify consistent themes. ${ }^{39}$ More than 1 code could be assigned to each participant's statement. We used a team approach to this inductive analysis, including meetings to discuss coded data and reach consensus on identified themes and their meanings. We iteratively discussed categories for reasons for participating and the interpretation and potential implications of our findings. Ten unique categories were identified; the frequency of each category is presented, along with exemplar participant quotes that are particularly representative.

\section{Results}

Of 503 patients referred, 118 patients (23\%) participated in at least 1 session of the ACP group visit intervention and 385 (76\%) did not participate, as shown in Figure 1. Sixteen cohorts participated; group sizes ranged from 4 to 11 patients. Of 118 patients, 97 patients participated in both sessions (82\% retention rate). One patient missed the first session but participated in the second session. Of 385 who did not participate based on the initial referral and telephone outreach call, the majority declined to be scheduled $(\mathrm{n}=293 ; 76 \%)$ and fewer patients were scheduled but canceled or did not show $(6.5 \%)$, were interested in a future date $(3.6 \%)$, or were unable to be reached (3.6\%). Nonparticipants were younger and less likely to have Medicare or TRICARE insurance as their primary insurance coverage. Among nonparticipants, 44\% did not give a reason, $19 \%$ had already completed an advance directive, $16 \%$ were not interested, and $17 \%$ had other reasons for not participating. Illness, moving, transportation issues, and already having had a conversation were uncommon reasons for declining to participate.

Table 1 shows the characteristics of the 118 patients who participated in the intervention. $\mathrm{Pa}$ tients had a mean age of 76 years; $62 \%$ were women, and $82 \%$ were white. Over one-fifth $(22 \%)$ reported being a caregiver in the past 12 months, and $7.6 \%$ described their overall health as fair or poor. A total of 73 participants were married (62\% of total), and 56 of these ( $47 \%$ of the total) attended the ACP group visit intervention with their spouse. Table 1 shows the referral source for participants. The majority (79\%) were referred by primary care providers, which included an in-person or letterbased recommendation to participate. Fourteen individuals $(12 \%)$ were self-referred through clinicbased flyers and contacted the program coordinator to be scheduled.

\section{ACP Documentation}

Figure 2 shows ACP documentation at baseline and after the ACP group visit intervention. From baseline to the 3-month follow-up, EMR documentation of a surrogate decision maker increased from 
Figure 1. Design for the advance care planning group visit intervention. This flowchart provides an overview of patients $(n=118)$ and nonparticipants $(n=385)$ who were referred for the intervention. At baseline, participants were scheduled for two 2-hour group visits, 1 month apart, with follow-up at 3 and 12 months. *0ne patient missed the first session but desired to participate in the second session. EMR, electronic medical record.

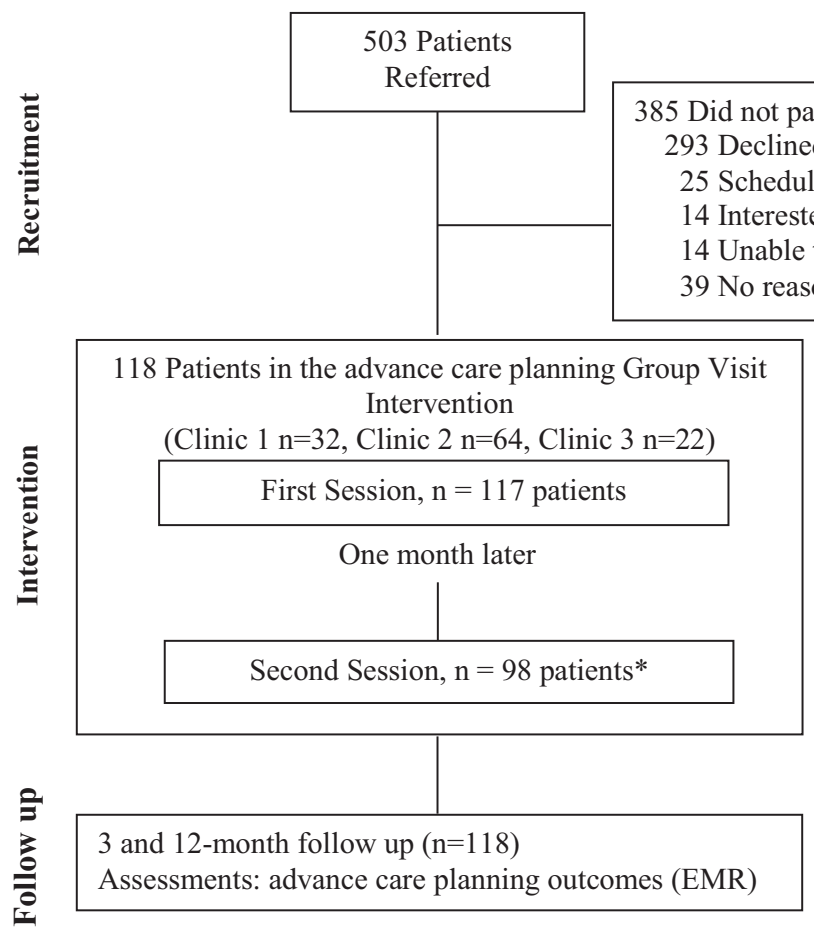

$39 \%$ to $81 \%(P<.001)$. At the 12 -month followup, the percentage increased to $89 \%(P<.001)$. The proportion of patients with at least 1 ACP document in the EMR increased from $20 \%$ at baseline to $57 \%$ at 3 months $(P<.001)$ and to $67 \%$ at 12 months $(P<.001)$. Among patients who had at least $1 \mathrm{ACP}$ document in the EMR, MDPOA forms and living wills were the most common forms on file at each time point (Figure 3).

\section{Reasons for Participating}

A total of 115 patient statements were grouped into 10 categories of reasons for participating in the ACP group visit intervention. Table 2 highlights exemplar quotes for each category. The most frequent reasons for participating were recognizing the need for ACP (30\%), recommendation by primary care providers (24\%), and curiosity and wanting to know more about the topic (20\%). Several patients described a desire to revisit existing advance directives or preferences (17\%), including because of relocating from a different geographic location $(2.6 \%)$. Others participated based on personal experiences with loved ones facing serious illnesses (15\%), a desire to talk with family (11\%), age as a motivating factor $(9.6 \%)$, or interest in completing an advance directive (7.0\%). Some learned about the intervention directly from program outreach such as clinic-based flyers $(12 \%)$, or through a suggestion from a spouse, family member, or friend $(8.7 \%)$. Four individuals did not provide a reason for participating.

Many patients described multiple factors that motivated their participation. For instance, 1 woman described recognizing the need for ACP, past personal experiences, and a desire to revisit existing advance directives, stating, "I am here to learn what I can. My husband passed away at the age of 67 back in 1995 and we had it set up[;] before that I wanted to be cremated. I am not on the verge of passing away, but I've been thinking about it, and I told my kids if I have to go to a nursing home, I will probably take cruises instead. So, that is my planning."

\section{Discussion}

An innovative 2-session ACP group visit intervention in 3 primary care clinics significantly increased 
Table 1. Baseline Characteristics of Advance Care Planning Group Visit Participants versus Nonparticipants

\begin{tabular}{|c|c|c|c|c|c|c|}
\hline Characteristics & $\begin{array}{l}\text { All Clinics } \\
(\mathrm{n}=118)\end{array}$ & $\begin{array}{l}\text { Clinic } 1 \\
(\mathrm{n}=32)\end{array}$ & $\begin{array}{l}\text { Clinic } 2 \\
(\mathrm{n}=64)\end{array}$ & $\begin{array}{l}\text { Clinic } 3 \\
(\mathrm{n}=22)\end{array}$ & $\begin{array}{l}\text { Nonparticipants } \\
\quad(\mathrm{n}=385)\end{array}$ & $P$ Value* \\
\hline Age (years), mean (SD) & $76(6.5)$ & $79(5.3)$ & $75(6.6)$ & $75(6.3)$ & $74(7.0)$ & .005 \\
\hline Female sex & $73(62)$ & $19(59)$ & $37(58)$ & $17(77)$ & $251(65)$ & .49 \\
\hline \multicolumn{7}{|l|}{ Race } \\
\hline Native American & $2(1.7)$ & $1(3.1)$ & $0(0)$ & $1(4.5)$ & \multirow[t]{4}{*}{ N/A } & \\
\hline Hispanic or Latino & $5(4.2)$ & $1(3.1)$ & $3(4.7)$ & $1(4.5)$ & & \\
\hline Black/African American & $13(11)$ & $7(22)$ & $5(7.8)$ & $1(4.5)$ & & \\
\hline Non-Hispanic white & $97(82)$ & $23(72)$ & $55(86)$ & $19(86)$ & & \\
\hline \multicolumn{7}{|l|}{ Relationship status } \\
\hline Married or with partner & $73(62)$ & $16(50)$ & $49(77)$ & $8(36)$ & \multirow[t]{4}{*}{ N/A } & \\
\hline Widowed & $27(23)$ & $9(28)$ & $11(17)$ & $7(32)$ & & \\
\hline Divorced or separated & $12(10)$ & $4(13)$ & $4(6.3)$ & $4(18)$ & & \\
\hline Single & $5(4.2)$ & $2(6.3)$ & $0(0)$ & $3(14)$ & & \\
\hline \multicolumn{7}{|l|}{ Self-reported health status ${ }^{\dagger}$} \\
\hline $\begin{array}{l}\text { Excellent/very good/ } \\
\text { good }\end{array}$ & $103(87)$ & $23(72)$ & $61(95)$ & $19(86)$ & \multirow[t]{2}{*}{ N/A } & \\
\hline Fair/poor & $8(7.2)$ & $4(13)$ & $1(1.6)$ & $3(14)$ & & \\
\hline $\begin{array}{l}\text { Caregiver for another } \\
\text { person }\end{array}$ & $26(22)$ & $7(22)$ & $15(23)$ & $4(18)$ & N/A & \\
\hline Attended with a spouse & $56(47)$ & $10(31)$ & $40(64)$ & $6(27)$ & N/A & \\
\hline \multicolumn{7}{|l|}{ Type of insurance ${ }^{\ddagger}$} \\
\hline Medicare & $112(96)$ & $32(100)$ & $60(94)$ & $20(91)$ & $301(78)$ & $<.001$ \\
\hline TRICARE & $63(54)$ & $17(53)$ & $39(61)$ & $7(32)$ & $148(38)$ & .005 \\
\hline Medicaid & $7(6.0)$ & $4(13)$ & $2(3.1)$ & $1(4.5)$ & $22(5.7)$ & .93 \\
\hline Other & $5(4.3)$ & $2(6.3)$ & $1(1.6)$ & $2(9.1)$ & $51(13)$ & $<.001$ \\
\hline \multicolumn{7}{|l|}{ Education } \\
\hline Less than high school & $1(0.8)$ & $1(3.1)$ & $0(0)$ & $0(0)$ & \multirow[t]{5}{*}{ N/A } & \\
\hline High school graduate & $19(16)$ & $3(9.4)$ & $12(19)$ & $4(18)$ & & \\
\hline Some college & $29(25)$ & $7(22)$ & $18(28)$ & $4(18)$ & & \\
\hline College graduate & $26(22)$ & $7(22)$ & $13(20)$ & $6(27)$ & & \\
\hline Postgraduate/professional & $38(32)$ & $10(31)$ & $20(31)$ & $8(36)$ & & \\
\hline \multicolumn{7}{|l|}{ Referral source } \\
\hline Primary care provider & $93(79)$ & $24(75)$ & $50(78)$ & $19(86)$ & \multirow{4}{*}{ N/A } & \\
\hline Spouse/partner & $9(7.6)$ & $2(6.3)$ & $7(11)$ & $0(0)$ & & \\
\hline Self-referred & $14(12)$ & $4(13)$ & $7(11)$ & $3(14)$ & & \\
\hline Friend & $2(1.7)$ & $2(6.3)$ & $0(0)$ & $0(0)$ & & \\
\hline
\end{tabular}

Data are $\mathrm{n}(\%)$ unless otherwise indicated. The table compares participants in all clinics $(\mathrm{n}=118)$ with nonparticipants $(\mathrm{n}=385)$ for age, sex, and type of insurance.

*All participants vs nonparticipants.

${ }^{\dagger}$ Health status was reported during check-in at the first session.

${ }^{\ddagger}$ More than one insurance type could be listed.

N/A, not available.

ACP documentation of surrogate decision makers and ACP documents in the medical record at both 3 and 12 months following the intervention. One year after participating, $89 \%$ of patients had chosen a surrogate decision maker and $67 \%$ had an ACP document on file with the health care system. These results suggest that an ACP group visit intervention could assist the $73 \%$ of adults aged $\geq 65$ years who have not discussed end-of-life care with a physician (2015 survey) and the $40 \%$ who have not documented end-of-life care wishes (2013 survey). ${ }^{3}$ This report extends prior work demonstrating that older adults are willing to engage in ACP conversations during group medical visits. ${ }^{31}$ These ACP discussions via group visits can be implemented at the practice level and billed for using the Medicare Current Procedural Terminology codes to reimburse clinicians for ACP counseling. ${ }^{40}$ 
Figure 2. Documentation of advance care planning (ACP) among group visit participants $(\mathrm{n}=118)$ at baseline and the 3- and 12-month follow-ups. Patient documentation of surrogate decision makers and ACP forms at baseline and at 3 and 12 months. The comparisons of baseline versus 3 months and baseline versus 12 months are significant at $P<.001$.

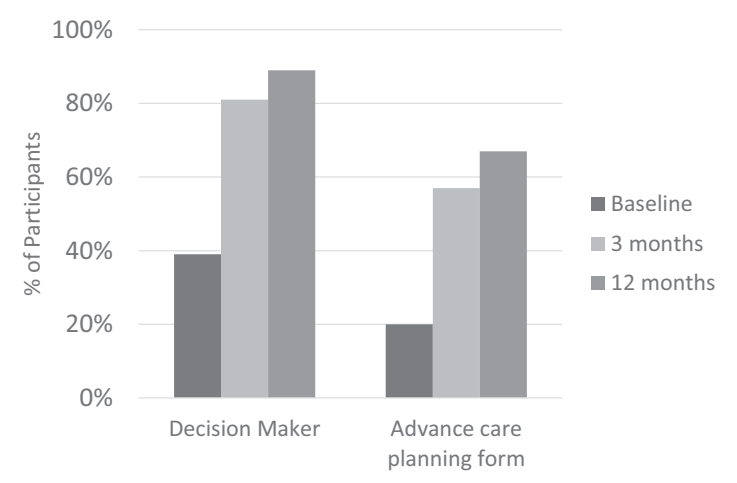

While most of the participants reported at least "good" health status, a few individuals declined based on illness. This intervention warrants specific adaptation and testing for specialty populations who have chronic or potentially limiting conditions, such as a cancer or cognitive impairment. Such interventions can be adapted based on input from patients, families, and health care providers.

In terms of feasibility and potential future implementation, participants' reasons for participating were substantially diverse; they included recognizing the need for ACP, encouragement from primary care providers, and curiosity and desire to learn. Others were motivated by wanting to complete specific actions such as talking about ACP with family or friends, or completing new or revising existing advance directives. Understanding what motivates patients to participate is important for designing program outreach strategies to better reach patients who may be ready to discuss ACP in the group visit setting. Specifically, recommendation by or referral from primary care providers may be a key implementation strategy. ${ }^{12}$ We used multiple recruitment methods to invite patients to participate. In an exploratory analysis, we noticed insurance type varied for participants compared with nonparticipants. The reason for this is unclear, and we do not have enough information about nonparticipants to elucidate potential reasons for not participating. Additional work is needed to understand whether recruitment or counseling strategies are available to help people consider participating in an
ACP group visit even if they are not initially interested. Broadly, future study is needed to determine how to best identify patients who are ready to engage in ACP and what methods of ACP intervention (ie, 1-on-1, group visits, websites, videos) best meet individuals' needs.

The ACP group visit intervention is a teambased model that is designed, but not limited to, medical care home models. Systematic and narrative reviews of ACP interventions in primary care settings emphasize the need for sustainable interventions. ${ }^{41}$ Simultaneously, there is an increased focus on ACP as a measure of patient-directed, high-quality health care. The National Committee for Quality Assurance's 2014 patient-centered medical home standards include a quality metric related to advance directive documentation. ${ }^{42}$

This study has particular implications for systems-based approaches to patient recruitment for ACP group visits. For example, primary care provider-based outreach and clinician referral in a small geriatrics clinic showed recruitment rates of $40 \%$ to the ACP group visit. ${ }^{31}$ For this 2-year project involving implementation in 3 primary care clinics, the overall recruitment rate was $23 \%$, which is typical of group visit studies involving older adults and other medical topics. ${ }^{23,43,44} \mathrm{We}$ used multiple recruitment techniques, including reaching out to primary care providers in each clinic, sending invitation letters to patients with the permission of the patient's primary care provider, and using clinic-based flyers. While letters are more easily operationalized and scalable than relying on individual recommendation from the primary care provider to the patient, comparison of effective and

Figure 3. The type of advance care planning forms among group visit participants $(n=118)$ at baseline and at the 3- and 12-month follow-ups. Specific forms were available in the participants' electronic medical records. Participants could have $>1$ type of advance care planning form.

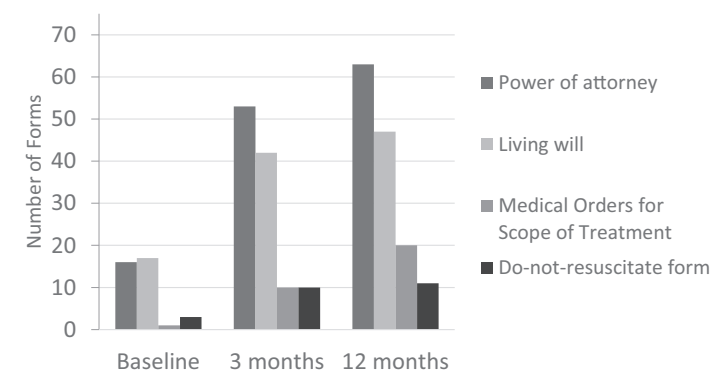


Table 2. Patient's Reasons for Participating in the Advance Care Planning Group Visit

\begin{tabular}{|c|c|c|}
\hline Category & $\begin{array}{c}\text { Participant } \\
\text { Mentions, n (\%) }\end{array}$ & Exemplar Quote \\
\hline $\begin{array}{l}\text { Recognizes importance of } \\
\text { advance care planning }\end{array}$ & $34(30 \%)$ & $\begin{array}{l}\text { "I want to get everything taken care of so my kids don't have to do it and } \\
\text { they will know exactly what to do when the time comes. My mother } \\
\text { and dad did that for me." } \\
\text { "I feel this is going to be good for me too. It's something that my } \\
\text { husband and I need to think about. We were hoping it would help out } \\
\text { [our daughter, now deceased], and I know now that it's something that } \\
\text { we all have to think about." }\end{array}$ \\
\hline $\begin{array}{l}\text { Recommended by primary } \\
\text { care provider }\end{array}$ & $27(24 \%)$ & $\begin{array}{l}\text { "We [a married couple] were advised by our primary care physician to } \\
\text { attend the meeting and so we're here to learn." }\end{array}$ \\
\hline Curiosity & $23(20 \%)$ & $\begin{array}{l}\text { "I'm here because I wanted to know what you have to say, know what } \\
\text { other people are thinking. There are some things I've had problems } \\
\text { with making decisions on. . . . Mainly I wanted to know what other } \\
\text { people are thinking and planning especially with the life support." } \\
\text { "I'm his wife. Some time ago we made the will, or whatever you call it. } \\
\text { And we have } 8 \text { children. They are very supportive. They don't want to } \\
\text { talk about this, so we really haven't . . but I have no worries. I'm } \\
\text { interested to see what is here." }\end{array}$ \\
\hline $\begin{array}{l}\text { Revisit existing advance } \\
\text { directive forms }\end{array}$ & $\begin{array}{l}19(17 \%) \text {, including } \\
3(2.6 \%) \text { related } \\
\text { to relocating }\end{array}$ & $\begin{array}{l}\text { "We've done quite a bit of paperwork and stuff, but I keep seeing things } \\
\text { that apparently we are missing or something like that. And we probably } \\
\text { will have to redo things, like a will or something. It's been a long time. } \\
\text { But I'd just like to make sure. Cause every time I have these forms, } \\
\text { they are different. And I get different stories about them." } \\
\text { "I've only been in Colorado about a year and a half and each state does } \\
\text { things differently. I had some of the stuff already done when I lived in } \\
\text { Texas. I really don't know if it's good here or not, so I'm here to get } \\
\text { information and see if what I do have is any good or not." }\end{array}$ \\
\hline Personal experiences & $17(15 \%)$ & $\begin{array}{l}\text { "I was [my husband's] caretaker this past year and he passed away less } \\
\text { than a year ago. What brings me here is the fact that he was in really } \\
\text { good health. He was a skier at } 76 \text { and it was cancer and the surgery did } \\
\text { not go well and he was in ICU for } 45 \text { days and never came home. He } \\
\text { did leave medical directives but it turned out not to be as } \\
\text { comprehensive as I think I would like mine to be." }\end{array}$ \\
\hline Outreach by letter, call, flyer & $14(12 \%)$ & $\begin{array}{l}\text { "I saw your poster. And I was having an appointment with [Dr. M.], who } \\
\text { is my primary care [provider] and she asked me if I would be interested } \\
\text { and I said yes." }\end{array}$ \\
\hline Desire to talk with family & $13(11 \%)$ & $\begin{array}{l}\text { "I have three sons and they don't want to hear anything about it... . wish } \\
\text { I had a daughter. I'll have to impress upon them what I want." }\end{array}$ \\
\hline Age & $11(9.6 \%)$ & $\begin{array}{l}\text { "I'm not a spring chicken any more, better start thinking about putting } \\
\text { things in order. We talked about the attorney or the medical living will } \\
\text { and so on. It's always good to get all those things in order." } \\
\text { "Why I am here? Because I'm old [laughing] like all of us here and of the } \\
\text { decision that we either avoid making or it's never the right time and } \\
\text { that may be something that, you know, I'll find out a little bit more } \\
\text { what is the right direction, what do I envision for myself." }\end{array}$ \\
\hline Suggested by loved ones & $10(8.7 \%)$ & $\begin{array}{l}\text { "I just came because my children thought maybe I should get some help!" } \\
\text { "I hadn't begun to think of any of these questions in my own mind, but } \\
\text { we received a form letter of inquiry about the group session and } \\
\text { through the diligence and organization of my wife, we're here and } \\
\text { hope to gain a lot." }\end{array}$ \\
\hline $\begin{array}{l}\text { Complete advance directive } \\
\text { forms }\end{array}$ & $8(7.0 \%)$ & $\begin{array}{l}\text { "I just wanted to make sure that the formal forms or whatever are } \\
\text { available to medical personnel so that my wishes, as far as end-of-life } \\
\text { issues are followed-what I want done, or not done." } \\
\text { "I'm here really to figure out what forms do I file where and so forth. It's } \\
\text { sort of confusing to me." }\end{array}$ \\
\hline
\end{tabular}

We identified 115 statements from intervention participants and analyzed their stated reasons for attending the advance care planning group visit. Percentages are $>100 \%$ because $>1$ reason could be coded per participant statement. Four participant statements (3.5\%) did not have an identifiable reason (eg, "I'm just here"). 
sustainable recruitment strategies is needed. Future studies should develop and test sustainable recruitment strategies that augment health care provider referrals and are integrated into existing teambased workflows, leverage clinic population-based registries, and use EMR and patient messaging outreach tools. ${ }^{45,46}$ Next steps in refining the intervention include determining how primary care providers want this model of care to be integrated into their practice, including best recruiting practices, communication from group visit facilitators to primary care providers, and arranging appropriate follow-up.

This study has several limitations to generalizability. Patients reflect the academic medical center primary care population aged $>65$ years and were mostly women, white, and educated. In the future, an ACP group visit could be adapted to meet the needs of particular populations, such as integrating into existing group visits for specific populations (ie, diabetes or mental health). By design, this is a clinical demonstration project that was integrated into 3 clinics, all of which have previous experience with group visits. This eased some of the requirements in developing workflows and clinical leadership support for implementing a novel group visit related to ACP. For the focused analysis of participant's reasons for participating, we did not perform latent content analysis, which would deepen our understanding of the participant's contextual meaning around participation. In addition, we could not explore potential relationships based on sociodemographic characteristics.

\section{Conclusions}

The ACP group visit intervention significantly increased ACP documentation of surrogate decision makers and goals for future medical care among older adults in primary care clinics. Patients had a wide range of motivating factors that led them to participate in the initiative. The intervention warrants effectiveness testing in a randomized controlled trial to determine whether the model improves patient-centered ACP outcomes (ie, discussions, self-efficacy, and ACP documentation) compared with a control arm. Concurrently, given the need for sustainable ACP interventions in realworld settings, implementation research related to implementation strategies that maximize fidelity while allowing for flexible adaptation to clinical settings is also critical. This intervention may be well suited for health care systems that are increasingly using group visits to provide efficient care that is person-centered and associated with high levels of patient satisfaction.

The authors thank John Scott, MD, a pioneer in group medical visits since 1991, who established and taught many patients and health care providers the value of group medical visits and has been discussing ACP in this context for over a decade. Ingrid Lobo, MD, is a current champion for group medical visit implementation at our institution and laid the foundation for the development of this ACP group visit. The authors appreciate the clinical excellence of the University of Colorado Hospital primary care clinic staff who assisted with implementation and conduct of this project, including Patricia Schulof, LCSW, who served as the social worker in the group visit intervention. Sue Felton, MA, and Dana Lahoff, LCSW, assisted with project coordination, participant recruitment, and evaluation.

To see this article online, please go to: http://jabfm.org/content/ 30/4/480.full.

\section{References}

1. Institute of Medicine. Dying in America: improving quality and honoring individual preferences near the end of life. Washington, DC: National Academies Press; 2015.

2. Osborn R, Moulds D, Squires D, Doty MM, Anderson C. International survey of older adults finds shortcomings in access, coordination, and patientcentered care. Health Aff (Millwood) 2014;33: 2247-55.

3. Griffin S, Cubanski J, Neuman T, Jankiewicz A, Rousseau D, Foundation KF. Medicare and end-oflife care. JAMA 2016;316:1754.

4. McMahan RD, Knight SJ, Fried TR, Sudore RL. Advance care planning beyond advance directives: perspectives from patients and surrogates. J Pain Symptom Manage 2013;46:355-65.

5. Tierney WM, Dexter PR, Gramelspacher GP, Perkins AJ, Zhou XH, Wolinsky FD. The effect of discussions about advance directives on patients' satisfaction with primary care. J Gen Intern Med 2001; 16:32-40.

6. Wright AA, Zhang B, Ray A, et al. Associations between end-of-life discussions, patient mental health, medical care near death, and caregiver bereavement adjustment. JAMA 2008;300:1665-73.

7. Silveira MJ, Kim SY, Langa KM. Advance directives and outcomes of surrogate decision making before death. N Engl J Med 2010;362:1211-8.

8. Sudore RL, Schickedanz AD, Landefeld CS, et al. Engagement in multiple steps of the advance care planning process: a descriptive study of diverse older adults. J Am Geriatr Soc 2008;56:1006-13.

9. Fried TR, Bullock K, Iannone L, O'Leary JR. Understanding advance care planning as a process of 
health behavior change. J Am Geriatr Soc 2009;57: $1547-55$.

10. Ahluwalia SC, Bekelman DB, Huynh AK, Prendergast TJ, Shreve S, Lorenz KA. Barriers and strategies to an iterative model of advance care planning communication. Am J Hosp Palliat Care 2015;32:817-23.

11. Spoelhof GD, Elliott B. Implementing advance directives in office practice. Am Fam Physician 2012; 85:461-6.

12. Kim SL, Tarn DM. Effect of primary care involvement on end-of-life care outcomes: a systematic review. J Am Geriatr Soc 2016;64:1968-74.

13. Ramsaroop SD, Reid MC, Adelman RD. Completing an advance directive in the primary care setting: what do we need for success? J Am Geriatr Soc 2007;55:277-83.

14. Sudore RL, Knight SJ, McMahan RD, et al. A novel website to prepare diverse older adults for decision making and advance care planning: a pilot study. J Pain Symptom Manage 2014;47:674-86.

15. Volandes AE, Mitchell SL, Gillick MR, Chang Y, Paasche-Orlow MK. Using video images to improve the accuracy of surrogate decision-making: a randomized controlled trial. J Am Med Dir Assoc 2009; 10:575-80.

16. Van Scoy LJ, Green MJ, Reading JM, Scott AM, Chuang CH, Levi BH. Can playing an end-of-life conversation game motivate people to engage in advance care planning? Am J Hosp Palliat Care 2016 Jan 1 [Epub ahead of print]. https://dx.doi. org/10.1177/1049909116656353.

17. Hammes BJ, Rooney BL, Gundrum JD. A comparative, retrospective, observational study of the prevalence, availability, and specificity of advance care plans in a county that implemented an advance care planning microsystem. J Am Geriatr Soc 2010;58:1249-55.

18. Austin CA, Mohottige D, Sudore RL, Smith AK, Hanson LC. Tools to promote shared decision making in serious illness: a systematic review. JAMA Intern Med 2015;175:1213-21.

19. Arnett K, Sudore RL, Nowels D, Feng CX, Levy CR, Lum HD. Advance care planning: understanding clinical routines and experiences of interprofessional team members in diverse health care settings. Am J Hosp Palliat Care 2016 Sept 6 [Epub ahead of print].

20. Lund S, Richardson A, May C. Barriers to advance care planning at the end of life: an explanatory systematic review of implementation studies. PLoS One 2015;10:e0116629.

21. Cherniack EP. The use of shared medical appointments in the care of the elderly. J Ambul Care Manage 2014;37:32-7.

22. Sikon A, Bronson DL. Shared medical appointments: challenges and opportunities. Ann Intern Med 2010;152:745-6.

23. Scott JC, Conner DA, Venohr I, et al. Effectiveness of a group outpatient visit model for chronically ill older health maintenance organization members: a 2-year randomized trial of the cooperative health care clinic. J Am Geriatr Soc 2004;52:1463-70.

24. Edelman D, Gierisch JM, McDuffie JR, Oddone E, Williams JW. Shared medical appointments for patients with diabetes mellitus: a systematic review. J Gen Intern Med 2015;30:99-106.

25. Jaber R, Braksmajer A, Trilling JS. Group visits: a qualitative review of current research. J Am Board Fam Med 2006;19:276-90.

26. Cohen S, Hartley S, Mavi J, Vest B, Wilson M. Veteran experiences related to participation in shared medical appointments. Mil Med 2012;177: 1287-92.

27. Bronson DL, Maxwell RA. Shared medical appointments: increasing patient access without increasing physician hours. Cleve Clin J Med 2004;71:369-370, 372, 374 passim.

28. Eisenstat SA, Ulman K, Siegel AL, Carlson K. Diabetes group visits: integrated medical care and behavioral support to improve diabetes care and outcomes from a primary care perspective. Curr Diab Rep 2013;13:177-87.

29. Housden L, Wong ST, Dawes M. Effectiveness of group medical visits for improving diabetes care: a systematic review and meta-analysis. CMAJ 2013; 185:E635-44.

30. Shared medical appointments/group visits. Leawood, KS: American Academy of Family Physicians; 2017. Available from: http://www.aafp.org/about/policies/all/ shared-medical.html. Accessed April 17, 2015.

31. Lum HD, Jones J, Matlock DD, et al. Advance care planning meets group medical visits: the feasibility of promoting conversations. Ann Fam Med 2016;14: 125-32.

32. Berger-Fiffy J. The "nuts and bolts" of implementing shared medical appointments: the Harvard Vanguard Medical Associates experience. J Ambul Care Manage 2012;35:247-56.

33. Ogrinc G, Davies L, Goodman D, Batalden P, Davidoff F, Stevens D. SQUIRE 2.0 (Standards for QUality Improvement Reporting Excellence): revised publication guidelines from a detailed consensus process. BMJ Qual Saf 2015;25:986-92.

34. Bruffee KA. Collaborative learning: higher education, interdependence, and the authority of knowledge. Baltimore: Johns Hopkins University Press; 1993.

35. The Conversation Project. Starter kits. Available from: http://theconversationproject.org/starter-kit/ intro/. Accessed October 13, 2012.

36. Hays RD, Spritzer KL, Thompson WW, Cella D. U.S. general population estimate for "excellent" to "poor" self-rated health item. J Gen Intern Med 2015;30:1511-6.

37. Hays RD, Bjorner JB, Revicki DA, Spritzer KL, Cella D. Development of physical and mental health 
summary scores from the patient-reported outcomes measurement information system (PROMIS) global items. Qual Life Res 2009;18:873-80.

38. Fereday J, Muir-Cochrane E. Demonstrating rigor using thematic analysis: a hybrid approach of inductive and deductive coding and theme development. Int J Qual Methods 2010;5:80-92.

39. Crabtree BF, Miller WL. Doing qualitative research, 2nd ed. Thousand Oaks, CA: Sage Publications; 1999.

40. Centers for Medicare and Medicaid Services. CMS finalizes 2016 Medicare payment rules for physicians, hospitals \& other providers," October 30, 2015 [press release]. Available from: https://www. cms.gov/Newsroom/MediaReleaseDatabase/Pressreleases/2015-Press-releases-items/2015-10-30. html. Accessed October 31, 2015.

41. Glaudemans JJ, Moll van Charante EP, Willems DL. Advance care planning in primary care, only for severely ill patients? A structured review. Fam Pract 2015;32:16-26.
42. National Committee for Quality Assurance. PCMH 2011-PCMH 2014 crosswalk. Available from: http:// www.ncqa.org/programs/recognition/practices/ patient-centered-medical-home-pcmh/pcmh-2011pcmh-2014-crosswalk. Accessed May 8, 2016.

43. Riley SB. Improving diabetes outcomes by an innovative group visit model: a pilot study. J Am Assoc Nurse Pract 2013;25:466-72.

44. May SG, Cheng PH, Tietbohl CK, et al. Shared medical appointments to screen for geriatric syndromes: preliminary data from a quality improvement initiative. J Am Geriatr Soc 2014;62:2415-9.

45. Tieu C, Chaudhry R, Schroeder DR, Bock FA, Hanson GJ, Tung EE. Utilization of patient electronic messaging to promote advance care planning in the primary care setting. Am J Hosp Palliat Care 2016 Jan 1 [Epub ahead of print]. https:// dx.doi.org/10.1177/1049909116650237.

46. Kruse CS, Bolton K, Freriks G. The effect of patient portals on quality outcomes and its implications to meaningful use: a systematic review. J Med Internet Res 2015;17:e44. 